\title{
RECYCLING OF SMALL ELECTRICAL MACHINES AND ITS APPLICATIONS FOR LOW COST WIND TURBINES.
}

\author{
A. Gálvez ${ }^{2}$, M. Lejárraga ${ }^{3}$ J. S. Artal ${ }^{1}$, A. Usón ${ }^{1}$ and F. J. Arcega ${ }^{1}$. \\ ${ }^{1}$ Department of Electrical Engineering. \\ E.U.I.T.I., University of Zaragoza. \\ Campus Tecnológico del Actur. \\ María de Luna, 3. Edificio C, 'Torres Quevedo'. 50018, Zaragoza (Spain). \\ Phone:+34 976762589 , Fax:+34 976762226.

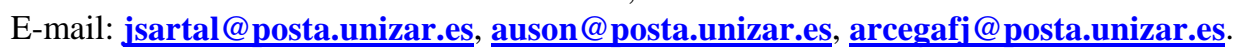 \\ ${ }^{2}$ DISTEL radiotelefonía S.L. \\ E-mail: antigonef@able.es \\ ${ }^{3}$ Phone: +34976621105 \\ Mobil phone: +34 620517603
}

\begin{abstract}
Nowadays, recycling issues has reached also the electrical machines engineering. Paper as "Principios de Diseño para Reciclar Motores de Inducción" [1] is an example of the interest of this matter within the engineers and professor all around the world. Students seem to be particularly interested in recycling, especially if its is applied to energy generation [2]. Fractional horsepower electrical motors, which can be found in any home appliances, as washing machines, hovers, mixers, etc., and automotion are the preferred machines as they are very easy to find and they are be simply to handle and operate [3]. The transformation of these machines into generators is not difficult, but it is a good exercise for students as it demands a deep knowledge of the electrical theory [4]. Energy generated by these machines is always stored in batteries and accumulators, so it can be applied to move electrical water pumps, drip irrigation systems, and to provide energy to isolated farmhouses [5]. The final purpose of this paper is to give ideas of how to make the lowest cost energy generator, both in terms of money and environmental impact.
\end{abstract}

A few years ago, our department started some projects and prototypes in the electrical recycling area. The great interested showed by the students and the quality of the experimental designs presented, have lead us to carry out this paper. Along this work, some of these samples are depicted, trying to show an objective vision of the matter. We will not included energy efficiency issues and energy losses of the recycled machines as they are not the main reason of the studies. Former prototypes shall focus in how to improve the isolation category of the generator, as it new location is quite different from the one which was design for.

\section{Keywords}

Recycling, low cost, fractional horse electrical machines, wind energy turbines, sustainable development.

\section{Introduction}

The great development of the renewable energies during the last ten years, specially the wind energy applications, has caused an important impact in engineering students, as it's a environmental friendly way of energy generation, and it has a great growth potential. If the idea of a clean energy generation is added to another attractive issue as the recycling, the result is a new contribution to the sustainable development. We think all these ideas shall become part of the new sybillus in technical colleges, so we have started working with final studies thesis. At the present time, we are focused in how can any small electrical motor be converted into a generator, using the bi-directional operation inherent in these machines (motor $\leftrightarrow$ generator). The possibilities are many, because the principle of operation of these small machines can vary from one appliance to the other (universal motors, single phase induction motors, reluctance motors,...). All them are important for the knowledge of the electrical machines student. Also we find very interesting how to recycle all electrical equipment from auto-motion applications.

Another part of the whole work is the design of the turbine, which shall be connected to the generator. Mainly, it can be either a micro-hydraulic turbine or a small wind turbine. We must also think in those machines that have already turbines, as fans and pumps, which can have the same bi-directional property as the electrical machine.

All these machines are not complicated to make and shall have a low cost, as they are made from used equipment very easy to find anywhere. Most common applications shall be agriculture and farming, where they can be a complement of small fuel power plants, in order to save fuel or gasoline that can be expensive and difficult to find, in places as the third world. Also they can be used in any isolated spot where it is unthinkable to build a electrical distribution line.

The energy generated by these devices shall always be stored in batteries or accumulators. These elements which are part of all electrical equipment in vehicles can also be 
recycled. It is not, at the present time, part of our studies, but batteries' recycling is an issue that we can consider in the future. Following the same philosophy, the electronic regulation system shall be as simple and robust as possible. These characteristics lead to analogical electronic designs, due to the low and easy maintenance required and it low cost.

\section{Small wind turbine built from automotive recycled components.}

An electrical alternator of a car, bus, lorry, tractor, is the most simple example of a device which can be easily reused to generate electrical energy, without any change. In the case depicted in fig. 1, a wind turbine drives the alternator. Other device as the tail vane for yaw control was made from a windscreen wiper of a car. The electronic regulator was entirely designed with analogical techniques, using the same principle as the one used in the vehicles. The whole machine has been designed to match the power and speed of the alternator.

A small washing machine water pump was connected to the alternator shaft, intended to pump water for the irrigation of a small garden, orchard,... This device shall improve the energy conversion efficiency of the whole system, as its avoids mechanical-electrical-mechanical energy conversion losses.

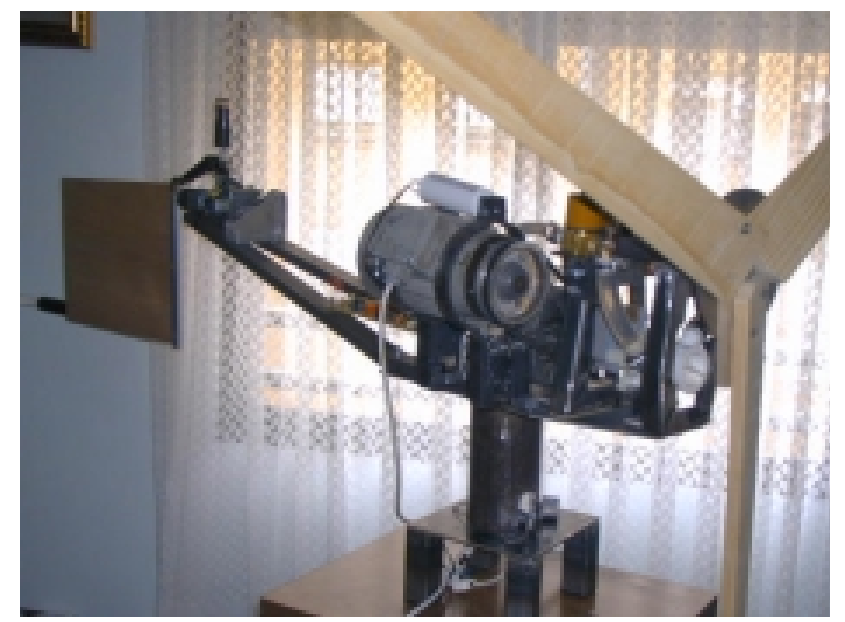

Figure 1. Prototype of the wind turbine built from automotive components.

Stored electrical energy in batteries is necessary in this turbine, as the alternator is not self-excited. In order to test the electronic regulator, a single-phase electrical motor was used to drive the generator, simulating the power from the wind turbine. This motor can be seen in fig. 1 and fig. 2, but it was latterly dismantled.

At the present time, college students from the industrial design courses are designing the nacelle that shall be placed to provide a shelter for the electric and mechanical equipment.

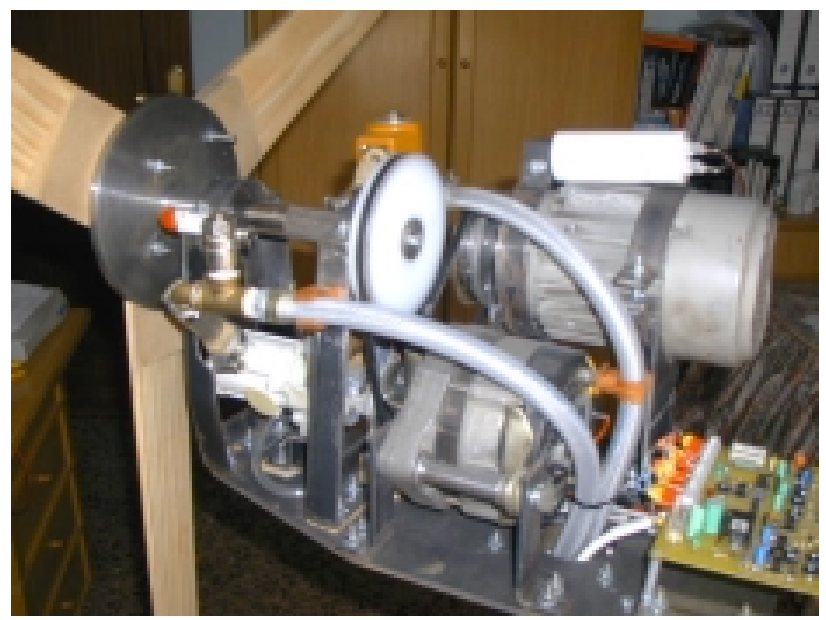

Figure 2. Rotor shaft, rotor pulley, belt, generator, water-pum, and the auxiliary electrical motor of the wind turbine.

\section{Transformation of a ceiling fan into a small wind turbine.}

Ceiling fans are very commonly used home appliances, consuming single-phase $230 \mathrm{~V}$ electrical energy. The fan is a bi-directional machine, so it can transform wind energy in mechanical energy without any change. In order to obtain electrical energy, it shall be necessary to make changes in the motor to obtain a generator. The design of these motors is very simple. They have sevenpair poles winding and an auxiliary shifted winding to create the starting torque. Both windings are fixed in the centre of the fan, and to the ceiling. The squirrel cage rotor is placed in the periphery and turn with the blades of the fan.

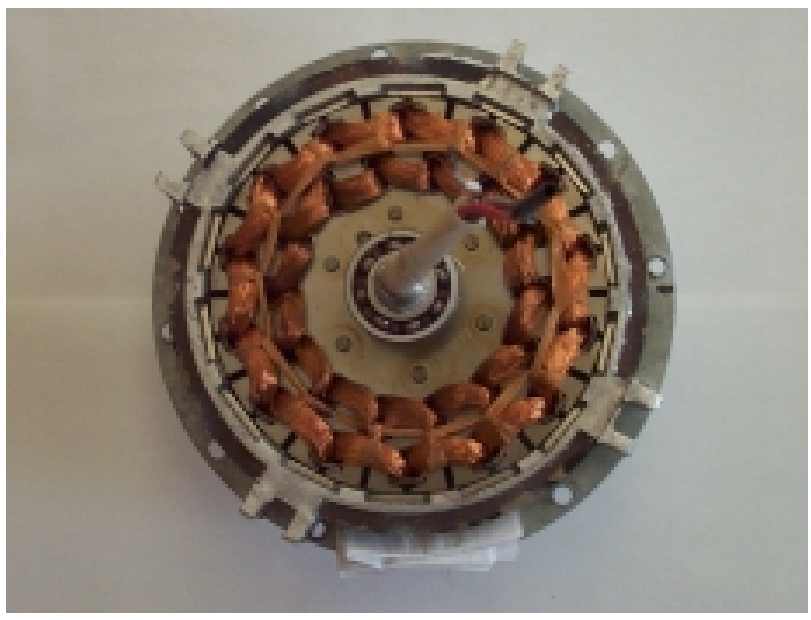

Figure 3. Fan motor transformed into a permanent magnet generator.

To transform this machine into a permanent magnets generator, we fixed 14 small magnets in the rotor, which create a magnetic flux path equivalent to the one created by the coils when working as motor. Comercial type Neodymium magnets (Neo.35 20x10x2,5mm) were used. As a result of this change, an electromagnetic force 
proportional to the revolution speed is obtained at the terminals of the windings (see fig. 3 and 4).

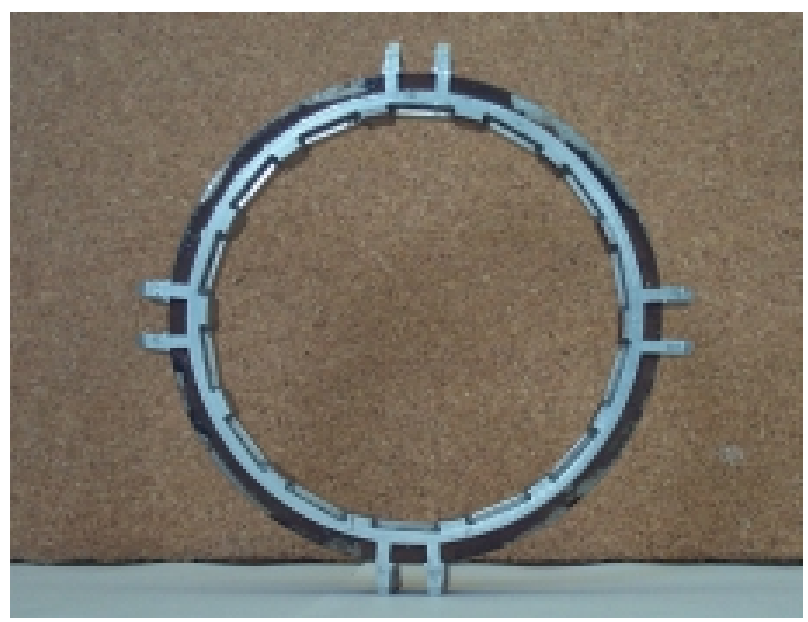

Figure 4. Fourteen pole rotor with permanent magnets

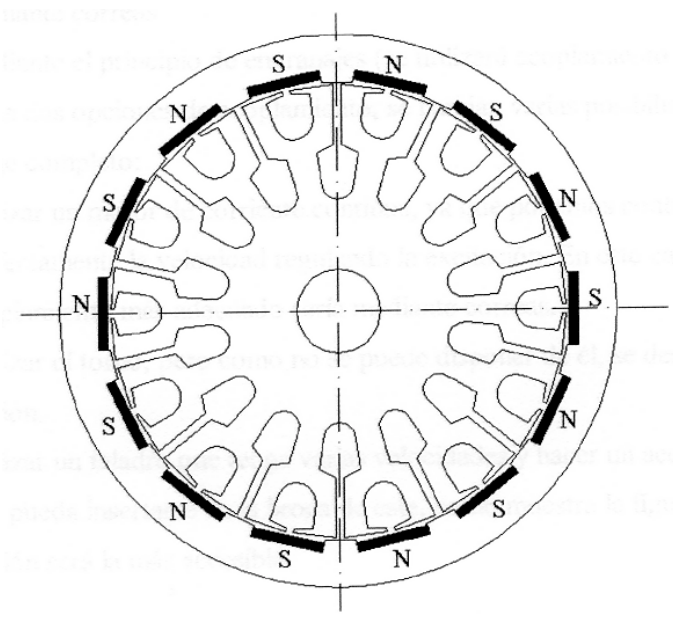

Figure 5. Rotor and stator of the transformed fourteen-pole motor.

Figure 4 and 5 show the structure of the rotor and the stator. The air spaces needed for the two windings are the reason of distortion in the electromotive force waveform. This phenomenon is particularly intense when the generator is loaded with high inductive load, and is compensated with the structure of the air gap showed in fig. 6 .

Figure 6 shows the magnet with a flat shape included in the rotor circular surface. Variations in the depth of the air gap $(\delta)$ helps the obtaintion of an electromotive force waveform with low harmonic distortion, as it can be seen in the electromotive force waveform depicted in fig. 7.

Water insulation was improved as the turbine is intended to work in the open air. Original ball bearings were replaced with water-pump bearings, rubber strips were placed to seal possible water entrances and the coating was reinforced with specific painting.
The four fan blades were rebuilt with treated wood, and its shapes were slightly changed to improve its efficiency.

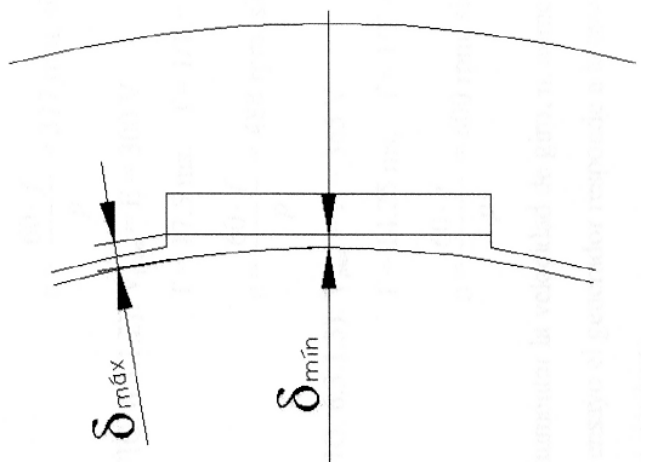

Figure 6. Air gap variations in the permanent magnet generator.

The following figures show examples of waveforms of voltage and current in the generator when loaded with different loads. Voltage is reference $\mathrm{A}$ and current reference B. In fig. 8 , the generator was loaded with a $230 \mathrm{~V}, 100 \mathrm{~W}$ electrical bulb. Waveform distortion in both waveforms is due to the armature reaction and the air spaces in the stator.

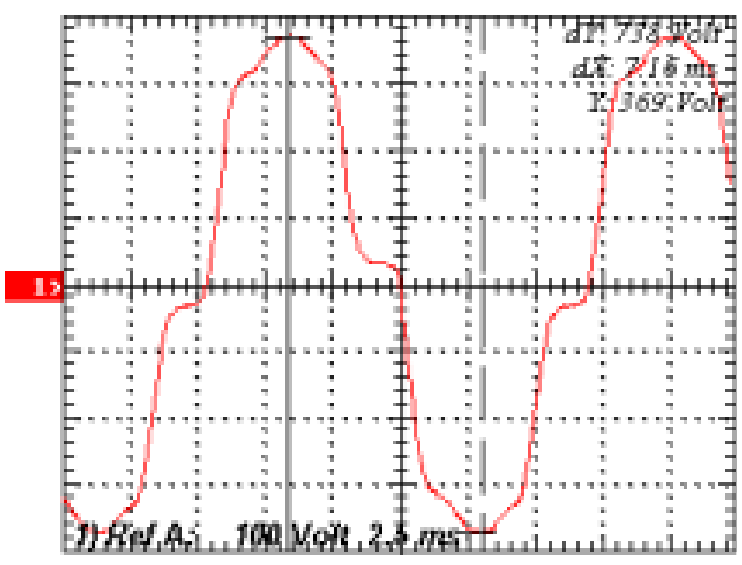

Figure 7. Unloaded generator. Rotation speed $600 \mathrm{rpm}$.

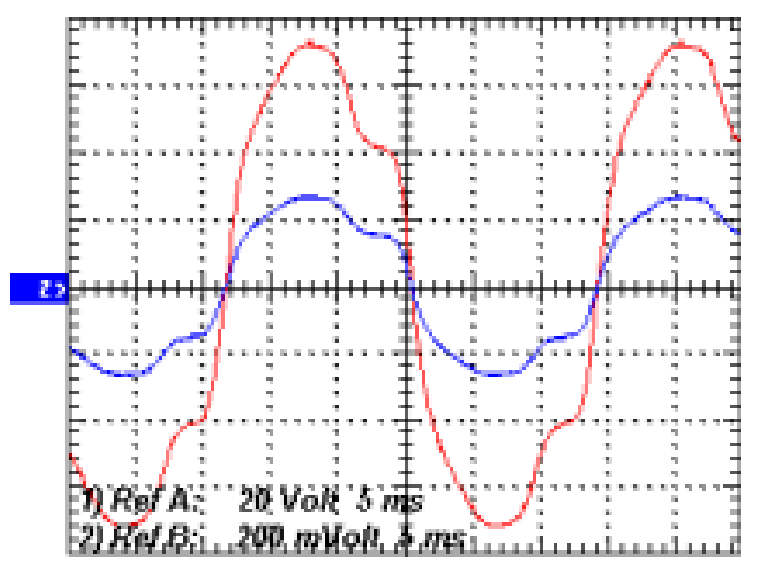

Figure 8. Resistive load. Rotation speed 375 rpm. 
Table 1. Comparison of results of C and RC load. (Figure 9 and 10).

\begin{tabular}{|c|c|c|c|c|}
\hline & $\begin{array}{c}\text { Ref A. (voltage). } \\
\text { Cload. }\end{array}$ & $\begin{array}{c}\text { Ref B. (current). } \\
\text { Cload. }\end{array}$ & $\begin{array}{c}\text { Ref A. (voltage). } \\
\text { RC load. }\end{array}$ & $\begin{array}{c}\text { Ref A. (current). } \\
\text { RC load. }\end{array}$ \\
\hline Period & $28,5 \mathrm{~ms}$ & $28,5 \mathrm{~ms}$ & $24,3 \mathrm{~ms}$ & $24,3 \mathrm{~ms}$ \\
\hline Frequency & $35,1 \mathrm{~Hz}$ & $35,1 \mathrm{~Hz}$ & $41,2 \mathrm{~Hz}$ & $41,2 \mathrm{~Hz}$ \\
\hline Pos. Pulse width & $14,2 \mathrm{~ms}$ & $14,2 \mathrm{~ms}$ & $12,1 \mathrm{~ms}$ & $12,1 \mathrm{~ms}$ \\
\hline Neg. Pulse width & $14,3 \mathrm{~ms}$ & $14,3 \mathrm{~ms}$ & $12,1 \mathrm{~ms}$ & $12,1 \mathrm{~ms}$ \\
\hline Shift & --- & $-84,8^{\circ}$ & --- & $-38,37^{\circ}$ \\
\hline Pos. Duty Cicle & $49,93 \%$ & $49,93 \%$ & $49,96 \%$ & $49,96 \%$ \\
\hline Neg. Duty Cicle & $50,07 \%$ & $50,07 \%$ & $50,04 \%$ & $50,04 \%$ \\
\hline Peak to Peak & $448 \mathrm{~V}$ & $780 \mathrm{~mA}$ & $358 \mathrm{~V}$ & $440 \mathrm{~mA}$ \\
\hline Maximum & $224 \mathrm{~V}$ & $380 \mathrm{~mA}$ & $176 \mathrm{~V}$ & $216 \mathrm{~mA}$ \\
\hline Minimum & $-224 \mathrm{~V}$ & $400 \mathrm{~mA}$ & $-178 \mathrm{~V}$ & $220 \mathrm{~mA}$ \\
\hline Mean & $-2,22 \mathrm{~V}$ & $38,1 \mathrm{~mA}$ & $-629 \mathrm{mV}$ & $4,62 \mathrm{~mA}$ \\
\hline RMS & $168 \mathrm{~V}$ & $250 \mathrm{~mA}$ & $127 \mathrm{~V}$ & $152 \mathrm{~mA}$ \\
\hline
\end{tabular}

Fig. 9 shows the two waveforms when the generator feeds a capacitive load of $4 \mu \mathrm{F}$, with a clean sinusoidal shape. This characteristic is due to the magnetising effect of the capacitive current.

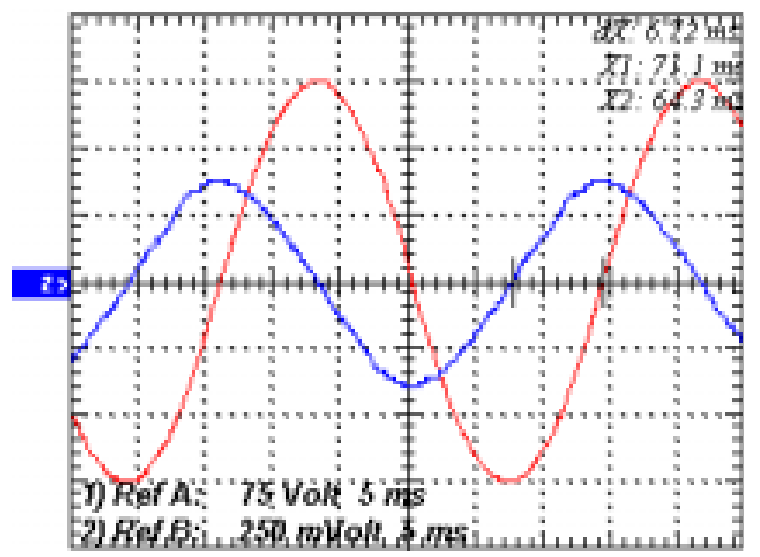

Figure 9. Capacitive load. Rotation speed $375 \mathrm{rpm}$.

Fig.10 was obtained adding to the former capacitive load an electric bulb of $230 \mathrm{~V}, 60 \mathrm{~W}$. The most significant values of these tests are showed in Table 1.

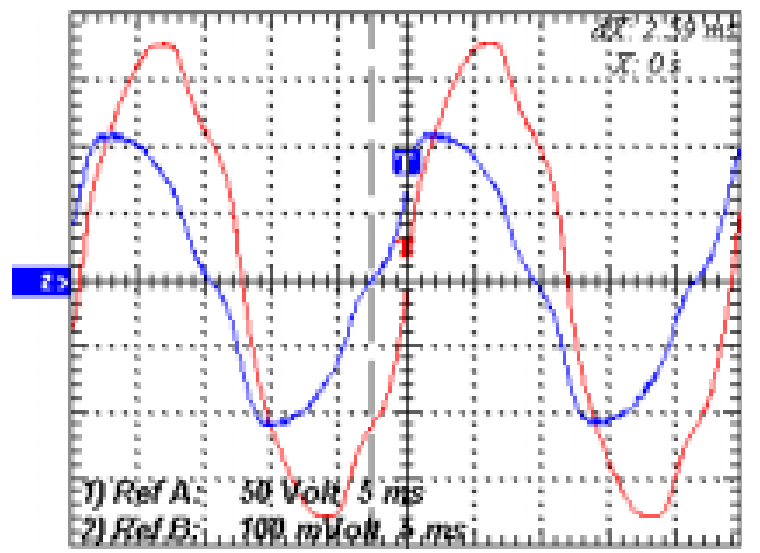

Figure 10. Resistive-Capacitive load. Rotation speed 375 rpm.

\section{Conclusions}

This paper tries to provide different solutions to make small electrical generators from recycled electrical materials. In one side, we work with fractional horse motors, which are the most common manufactured electrical machines, as they are the power drives in all home appliances. Also, automotive components can be easily recycled.

These generators shall be used in small wind turbines and micro hydroelectric power plants Its simple design, low cost, easy to find, are some of the qualities which make these generators a practical alternative in applications where a low energy consumption does not justify more expensive solutions. Also, they can be a realistic option in places where manpower costs (rewinding the motor, cleaning and lubrication... ) are negligible compared to the manufacturing cost.

Another aim of this work is to motivate students, joining both recycling techniques and renewable energies, which are essential for a sustainable development

\section{References}

[1]. R. Hernández, J. R. Pacheco, J. Salinas, "Principios de Diseño para Reciclar Motores de Inducción". VII Jornadas Hispano-Lusas de Ingeniería Eléctrica. Leganés, 2001 (Madrid). Pp 185 to 190.

[2]. J. I. Urquía y S. Urquía, "Energía Hidraúlica y Eólica práctica”. Ed. Gráficas Karrasi. Madrid, 1998.

[3]. E. R. Laithwaite, "Induction Machines for Special Purposes". Butterwoth \& C. (Publishers) Ltd., Londres. 1st Edition.

[4]. Wildi, Theodore, "Electrical Machines, Drives and Power System". Prentice Hall Inc. 4th Edition, 2000.

[5]. D. Le Gouriérès, "Energía Eólica, teoría, concepción y cálculo práctico de las instalaciones". Ed. Masson. Barcelona, 1983. 